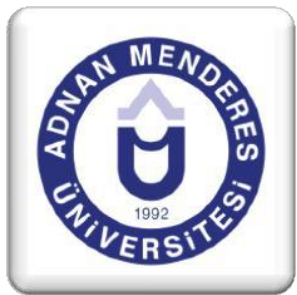

\section{Çocuk Kitapları Yoluyla Matematik Becerilerinin Kazandırılmasına Yönelik Yapılmış Araştırmaların İncelenmesi}

\author{
Gözde İNAL KIZILTEPE ${ }^{1}$, Ayșe ÖZTÜRK \\ SAMUR $^{2}$, Hilmi TEKİN ${ }^{3}$
}

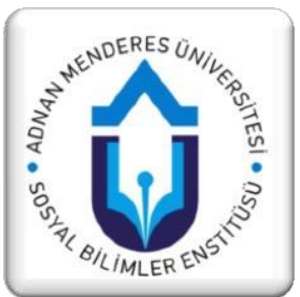

\title{
ÖZET
}

$\mathrm{Bu}$ araştırma, erken çocukluk döneminde matematik becerilerinin kazandırılmasında çocuk kitaplarının kullanılmasına ilişkin 2000-2016 yılları arasında yapılmış olan çalışmaların ulusal ve uluslararası düzeydeki durumunu değerlendirmek amacıyla yapılmıştır. Metodolojik değerlendirme çalışması olarak düzenlenen çalışmada veriler doküman analizi yoluyla elde edilmiştir. Araştırma, 2000-2016 yılları arasında yayınlanan EbscoHost, Elsevier Science Direct, Scopus, ISI Web of Knowledge - Web of Science ve Google Scholar veri tabanlarından tam metinlerine erişilen 40 adet çalışma ile sınırlıdır. Elde edilen veriler içerik analizi yöntemi ile çözümlenmiştir. Araştırma sonuçlarına göre; konuya ilişkin uluslararası düzeyde sınırlı sayıda çalışma yer almaktadır. Ulusal düzeyde ise erken çocukluk dönemini kapsayan çalışma bulunmamaktadır. Çalışmaların çoğunda nitel yöntem kullanılmıştır. İncelenen çalışmalarda sırası ile çocuklara matematik becerilerinin kazandırılmasında çocuk kitaplarının kullanılmasının önemi, çocuk kitaplarının nasıl kullanılacağı ve seçim kriterleri konuları ele alınmıştır.

Anahtar Kelimeler: Çocuk kitapları, matematik becerileri, erken çocukluk dönemi

\section{Analysis of the Studies which Examined Developing Mathematical Skills through Children's Books}

\begin{abstract}
This study has been carried out in order to identify status of the studies conducted both national and international scale about developing mathematical skills through children's books during early childhood period between 2000 and 2016. Qualitative research design was utilized and data was collected through document analysis. It is limited to 40 full text studies which were conducted on developing mathematical skills through children's books between 2000-2016 and were accessed through EbscoHost, Elsevier Science Direct, Scopus, ISI Web of Knowledge - Web of Science, adnd Google Scholar databases. Collected data was analyzed through content analysis method. According to the results of the study, the number of the studies is limited at international scale. There is no study about the subject that includes early childhood period at a national scale. Most of the studies utilized qualitative design. It is seen that in the studies examined in children's acquisition of mathematical skills, the significance of using children's books, how they would be used and selection criteria were discussed respectively.
\end{abstract}

Key words: Children's books, mathematical skills, early childhood period.

1 Dr.Öğr.Üyesi, Adnan Menderes Üniversitesi Eğitim Fakültesi Temel Eğitim Bölümü,Okul Öncesi Eğitimi Anabilim Dalıggozdeinal@gmail.com

2 Dr.Öğr.Üyesi,Adnan Menderes Üniversitesi Eğitim Fakültesi Temel Eğitim Bölümü, Okul Öncesi Eğitimi Anabilim Dalı, ayseozturksamur@yahoo.com

3 Öğr.Gör., Muğla Sıtkı Koçman Üniversitesi Muğla Meslek Yüksekokulu, Çocuk Bakımı ve Gençlik Hizmetleri Bölümü Çocuk Gelişimi Programı, hilmitekin@gmail.com 


\section{Giriş}

Karşılaşılan problemlerin çözümünde, hayatın sentezlenip yorumlanmasında, günün planlanmasında, mimaride, müzikte, aşçılıkta, resimde, dilde, hayatın her alanında matematik vardır. Galileo'nun dediği gibi "tabiat matematik dilinde yazılmıştır" ve yaşam yolculuğunda matematik büyük bir yol gösterici ve önemli bir dildir (Akt. Emiroğlu ve Görgülü, 2013).

Ancak matematik bilimlerin en soyutudur (Nesin, 2001). Soyut düşünebilmek ise zordur (Boaler ve Chen, 2016). Çocuklar soyut ve sayılardan oluşan bir dünya ile karşılaştıklarında genellikle matematiği erişilmez ve sıkıcı bulurlar. Hatalı ögretim programları nedeniyle çocuklar matematiksel olguları ezberler ve sayfalar dolusu sayıyla boğuşurlar. Matematik görsel ve yaratıcı bir şekilde çok az karşılarına çıkar. Oysa matematik, sadece matematik dersinin sınırları içerisinde hafızaya alınmış, test edilmiş ve içerilmesi gereken bir dizi kural ve formül değil, gerçek ve günlük yaşamın bir parçasıdır (Radebaugh, 1981). Matematik, bilişsel yeteneğin temel bileşenidir. Erken yaştaki matematiksel başarı, okumayı ve daha sonraki hayatta matematiksel yeteneği öngörür (Clements ve Sarama, 2009).

$\mathrm{Bu}$ nedenle okul yaşamında matematiğin korkulu rüya olmaktan çıkması, ileriki yıllarda kullanacağı matematik kavramlarını ve becerilerini geliştirebilmesi için; çocuk matematiği öğrenmeye, okul öncesi dönemde aktif öğrenme tekniklerinin kullanıldığı etkileşimli bir eğitim ortamında, eğlenceli etkinliklerle başlamalıdır (Wortham, 1998; Güven, 2000; Metin, 2001; Dinçer, 2008).

Özellikle 3-6 yaş çocuklarının matematikle ilgili öğrenme yaşantılarının ve öğretmenler tarafindan desteklenen matematik etkinliklerinin, bazen ayrı bir şekilde, bazen de çeşitli okul öncesi etkinlikleriyle birleştirilmiş çalışmaları içermesi gerekmektedir (NAEYC, 2002). Matematiğin diğer sınıf etkinlikleri ile bütünleştirilmesi, matematik öğrenimi güçlendirir (Arnold, Fischer, Doctoroff ve Dobbs, 2002). Hatta sadece etkinlikler dâhilinde değil, günün her anı matematik öğretimi için uygun sayılabilir. Örneğin çocuklar sıraya girdiği anda, öğretmenler çocukların matematik anlayışını geliştirmek için birçok firsat bulabilir (NAEYC, 2002). Okul öncesi eğitim programında yer alan tüm etkinlikler matematik için uygun firsatlar içermektedir (Avcı ve Dere, 2002). Matematik etkinlikleri, okullarda müzik, sanat, oyun, drama ve Türkçe etkinlikleri ile bütünleştirilerek, günlük rutin etkinliklere ve günlük yaşama dâhil edilerek çocukların daha etkileşimli, eğlenceli ve daha kalıcı bir şekilde matematik becerilerini öğrenmeleri sağlanabilir. Erken çocukluk yıllarındaki çocuklar, evlerinde, okullarında nitelikli ve çocuk merkezli etkinlikler yoluyla hem mevcut yaşamlarıyla ilgili, hem de gelecekteki matematiksel öğrenimleri için kritik bir temel oluştururlar (Kilpatrick, Swafford ve Findell, 2001; Perry ve Dockett, 2005).

Matematik öğretimi için çocuk edebiyatının kullanımı ilk defa 1989 yılında "Müfredat ve Okul, Matematik İçin Değerlendirme Standartları" konusuyla Matematik Öğretmenleri Ulusal Konseyinde tanıtılmıştır (Nesmith, 2008; Akt. Thomas ve Feng, 2015). Çocuk edebiyatının kullanımı yoluyla, matematiği ve birçok soyut kavramı anlamak mümkündür (Thomas ve Feng, 2015). İyi bir kitap, matematiği daha az korkutucu ve daha eğlenceli hale getirir (Radebaugh, 1981). Çocuklar kitaplar yoluyla matematik içeriği ile bağlantı kurabildiğinde, matematik daha ilginç, daha ilgi çekici ve gerçek hayattaki durumlara uygulanabilir olur. $\mathrm{Bu}$ nedenle çocuk kitapları, çocukları matematik kavramına veya becerisine hazırlamak, bu becerileri geliştirmek, gözden geçirmek, yaratıcı bir matematik 
deneyimine ilham vermek, ilginç bir problem oluşturmak veya problemlere açıklamalar geliştirmek için kullanılmalıdır (Welchman-Tischler,1992). Böylece öykü kitapları aracılığı ile matematiksel kavramlar görsel olarak sunularak, kavramlar somutlaşmakta ve çocuklar için daha anlamlı hale gelmektedir (Murphy, 1999; Callan, 2004; Goldstein 2007; Wilburne ve Napoli, 2008; Marston, 2010).

Öykü kitapları ile matematiğin birleştirilmesi, çocukların matematiksel bir içerik ile etkileşime geçmesi konusunda öğretmene de kolaylık sağlamaktadır (Van den HeuvelPanhuizen, Boogaard ve Doig, 2009). Öykü kitaplarının matematik öğretiminde kullanan öğretmenler daha interaktif bir öğrenme ortamına sahiptirler (Capraro ve Capraro, 2006). Aynı zamanda öykü kitapları ile matematiğin birleştirilmesi, öğretmene, matematiği, edebiyatı ve eleştirel düşünme becerilerini nasıl ilişkilendireceklerini göstermekte (Smith, 2013), öğrenmeyi bireyselleştirebilmeleri ve çocukların matematiksel anlayışlarındaki boşlukları doldurabilmeleri konusunda yardımcı olmaktadır (Goldstein 2007; Siebert ve Draper, 2008).

Alan yazın incelendiğinde, yurtdışında çocuk kitapları aracılı̆̆ 1 ile matematik becerilerinin kazandırılmasına ilișkin farklı eğitim kademelerinde nitel ve nicel desenler benimsenerek gerçekleştirilen çeşitli araştırmalara rastlanmaktadır (Elia, Van den Heuvel-Panhuizen ve Georgiou, 2010; Van den Heuvel-Panhuizen ve Elia, 2011; Marston, Muir, ve Livy, 2013; Van den Heuvel-Panhuizen, Elia ve Robitzsch, 2016). Türkiye'de yapılan çalışmaların ise çok sınırlı sayıda olduğu dikkat çekmektedir (Veziroğlu ve Gönen, 2012; İlter, 2014; Öçal, Öçal ve Şimşek, 2015). Ayrıca, yapılan inceleme sonucunda yurt içinde çocuk kitaplarının matematik becerilerinin kazandırılması amacıyla kullanılması konusunda gerçekleştirilen araştırmaların değerlendirildiği araştırmalara rastlanılmamıştır. Yurtdışı alan yazında ise, çocuk kitaplarının matematik becerilerinin kazandırılması amacıyla kullanılması konusunda gerçekleștirilen araștırmaların değerlendirildiği bir çalışma yer almaktadır (Van den HeuvelPanhuizen ve Elia, 2012). Bilimsel çalışmaların analiz edilmesi, o konunun derinliği ve yaygınlığı hakkında bilgi vermesi ve incelenen alanın genel görünümünü ortaya çıkarması bakımından önemlidir (Turan, Karadağ, Bektaş ve Yalçın, 2014). Bu bağlamda çalışmanın, çocuk kitaplarının matematik becerilerinin kazandırılması amacıyla kullanılması konusundaki yeni araştırmalara 1şık tutacağı düşünülmektedir. Bunun yanı sıra bu çalışma ile çocuk edebiyatının matematik becerilerinin kazandırılması amacıyla kullanılmasına ilişkin ulusal ve uluslararası düzeydeki çalışmaların, genel eğilimini belirleyecektir. Çalışmaların eksik yönlerinin ortaya çıkarılması ise bu alanda çalışma yapacak uzmanlara fikir verecektir.

$\mathrm{Bu}$ noktadan hareketle araştırmanın amacı, erken çocukluk döneminde matematik becerilerinin kazandırılmasında çocuk kitaplarının kullanılmasına ilişkin 2000-2016 yılları arasında yapılmış olan çalışmaların ulusal ve uluslararası düzeydeki durumunun değerlendirmesidir. Araştırmada aşağıdaki sorulara yanıt aranmıştır.

1. Matematik becerilerinin kazandırılmasında çocuk kitaplarının kullanımına ilişkin yapılan makalelerin yıllara göre dağılımı nasıldır?

2. Matematik becerilerinin kazandırılmasında çocuk kitaplarının kullanımına ilişkin yapılan makalelerin türlerine göre dağılımı nasıldır?

3. Matematik becerilerinin kazandırılmasında çocuk kitaplarının kullanımına ilişkin yapılan makaleler hangi temalar altında toplanmaktadır? 
4. Matematik becerilerinin kazandırılmasında çocuk kitaplarının kullanımına ilișkin yapılan araştırma makalelerinin yöntemlerinin dağılımı nasıldır?

5. Matematik becerilerinin kazandırılmasında çocuk kitaplarının kullanımına ilişkin yapılan araştırma makaleleri hangi çalışma grupları üzerinde gerçekleştirilmiştir?

\section{Yöntem}

\subsection{Araştırmanın Modeli}

$\mathrm{Bu}$ çalışma, bir metodolojik değerlendirme çalışması olarak düzenlenmiştir. Metodolojik değerlendirme yayımlanmış materyallerin çözümsel değerlendirmesidir (Karadağ, 2014) . Bu tür çalışmalarda, konu ile ilgili önceden yayımlanmış çalışmalar incelenerek düzenlendikten sonra, bir bütün haline getirilerek değerlendirilir ve üzerinde çalışılan araştırma alanındaki problem göz önüne serilir (Turan, Karadağ, Bektaş ve Yalçın, 2014). Bu özellikler dikkate alındığında, çocuk kitaplarının matematik becerilerinin kazandırılması amacı ile kullanılması konusundaki çalışmaların değerlendirilmesinin amaçlandığı bu çalışma için en uygun yöntemin metodolojik değerlendirme olduğuna karar verilmiştir.

\subsection{Evren ve Örneklem}

Araştırmada, erken çocukluk döneminde çocuk kitaplarının matematik becerilerinin kazandırılması amacı ile kullanılması konusunda yapılan çalışmaların değerlendirilmesi amaçlandığından, araştırmanın evreni 2000-2016 yılları arasında yayınlanan, EbscoHost, Elsevier Science Direct, Scopus, ISI Web of Knowledge - Web of Science ve Google Scholar veri tabanlarından tam metinlerine erişilen makalelerden oluşmaktadır. Araştırmada herhangi bir örnekleme yöntemine başvurulmamış, çalışma örnekleminin tamamına ulaşılması amaçlanmıştır. $\mathrm{Bu}$ doğrultuda konuya ilişkin erişilen 40 adet makale değerlendirilmiştir.

\subsection{Verilerin Toplanması ve Analizi}

Verilerin toplanmasında doküman analizi tekniğinden yararlanılmıştır. Araştırılması hedeflenen olay ve olgular hakkında bilgiler içeren yazılı materyallerin analizini kapsayan (Şimşek, 2009) doküman analizi, bir araştırma problemi hakkında belirli zaman dilimi içerisinde üretilen dokümanların geniş bir zaman dilimine dayalı analizini olanaklı kılmaktadır (Yıldırım ve Şimşek, 2000).

Doküman analizinin birinci aşamasında çalışma grubunda yer alan makalelerin tam metinlerine veri tabanlarından ulaşılmıştır. Makalelerin tam metinlerine "matematik eğitimi ve çocuk kitapları" (mathematics education and children books), "matematik eğitiminde resimli çocuk kitapları" (children picture books in mathematic learning) "matematik ve edebiyat" (mathematics and literature), "sayılar/ geometri ve çocuk kitapları" (number/geometry and children books) anahtar sözcükleri kullanılarak ulaşılmaya çalışılmıştır. Uluslararası düzeyde, erken çocukluk dönemini kapsayan çalışmalar dışında kalan makaleler örnekleme dâhil edilmemiştir. Ulusal düzeyde ise İlter (2014) tarafından yapılan makale çocuk edebiyatı aracılığı ile sosyal bilgilerin matematikle bütünleştirilmesine ilkokul ve ortaokul düzeyinde (4.5.6.7. ve 8. sınıf) odaklanması nedeniyle değerlendirme kapsamı dışında bırakılmıştır. Veziroğlu ve Gönen (2012)'in resimli çocuk kitaplarının okul öncesi eğitim programındaki kazanımlara uygunluğunun incelediği çalışma ise araştırmanın 
amacı dışında kaldığ için değerlendirmeye alınmamıştır.

$\mathrm{Bu}$ nedenle ulusal düzeyde erken çocukluk döneminde çocuk kitaplarının matematik becerilerinin kazandırılması amacı ile kullanılmasına yönelik sadece bir çalışma (Öçal, Öçal ve Şimşek, 2015) değerlendirmeye alınabilmiştir.

Erişilen makaleler, araştırmanın amaçları doğrultusunda; yıl, araştırmaların türleri ve desenleri, veri çalışma grupları ve temaları bakımından sınıflandırılmıştır.

Araştırma verilerinin analizinde içerik analizinden yararlanılmıştır. İçerik analizi, eldeki yazılı bilgilerin temel içeriklerinin ve içerdikleri mesajların özetlenmesi ve belirtilmesi işlemidir (Cohen, Manion ve Morrison, 2007). İçerik analizinde temel amaç, toplanan verileri açıklayabilecek kavramlara ve ilişkilere ulaşmaktır. Yıldırım ve Şimşek'e (2000) göre toplanan verilerin önce kavramsallaştırılması daha sonra da ortaya çıkan kavramlara göre mantıklı bir biçimde düzenlenmesi, buna göre veriyi açıklayan temaların saptanması gerekmektedir.

İçerik analizinde, dokümanlardan elde edilen verilerin kodlanması, temaların bulunması, kodların ve temaların düzenlenmesi, bulguların tanımlanması ve yorumlanması şeklinde dört aşama bulunmaktadır (Yıldırım ve Şimşek, 2000). Araştırmanın ilk aşamasında veriler anlamlı bütünlere ayrılarak benzer kodlarla düzenlenmiştir ve bu bağlamda çeşitli temalara ulaşılmıştır. $\mathrm{Bu}$ aşamadan sonra temalara göre veriler düzenlenerek gruplandırılmış ve uygun olduğu durumlarda veriler sayısal hale getirilerek sunulmuştur.

\section{Bulgular}

Araştırmanın bu bölümünde erken çocukluk döneminde çocuk kitaplarının matematik becerilerinin kazandırılması amacı ile kullanılması konusunda yapılan çalışmalara ilişsin bulgular, araştırmanın alt amaçları doğrultusunda sunulmuştur.

Araştırmanın birinci amacı; erken çocukluk döneminde çocuk kitaplarının matematik becerilerinin kazandırılması amacı ile kullanılması konusunda yapılan makalelerin yıllara göre dağılımını belirlemektir. Makalelerin yıllara göre dağılımına ilişkin elde edilen bulgular Tablo 1'de gösterilmiştir. 
Tablo 1. Erken çocukluk döneminde çocuk kitaplarının matematik becerilerinin kazandırılması amacı ile kullanılması konusunda yapılan makalelerin yıllara göre dağılımı

\begin{tabular}{ccccc}
\hline Yll & f & Yıl & f \\
\hline 2000 & 4 & 2009 & 2 \\
2001 & 2 & 2010 & 3 \\
2002 & 4 & 2011 & 2 \\
2003 & 3 & 2012 & 1 \\
2004 & 7 & 2013 & 1 \\
2005 & 1 & 2014 & 1 \\
2006 & 1 & 2015 & 1 \\
2007 & 1 & 2016 & 2 \\
2008 & 4 & & \\
\hline Toplam & & $\mathbf{4 0}$ &
\end{tabular}

Tablol'de görüldüğü gibi, yurtdışında erken çocukluk döneminde çocuk kitaplarının matematik becerilerinin kazandırılması amacı ile kullanılması konusunda en çok makalenin 2004 yılında yapıldı̆̆ı, 2000-2016 yılları arasında her yıl bu konuda yapılmış olan makalenin olduğu dikkati çekmektedir.

Araştırmanın ikinci amacı; erken çocukluk döneminde çocuk kitaplarının matematik becerilerinin kazandırılması amacıyla kullanılması konusunda yapılan makalelerin türlerine göre dağılımının belirlenmesi, üçüncü amacı ise makalelerin hangi temalar altında toplandığının belirlenmesidir. Bu amaçlar doğrultusunda ulaşılan bulgular Tablo 2'de sunulmuştur. 
Tablo 2. Erken çocukluk döneminde çocuk kitaplarının matematik becerilerinin kazandırılması amacı ile kullanılması konusunda yapılan makalelerin türlerine ve temalarına göre dağılımı

\begin{tabular}{|c|c|c|c|c|c|}
\hline \multicolumn{5}{|c|}{ Makale Türü } & \multirow[t]{3}{*}{ Temalar } \\
\hline \multicolumn{2}{|c|}{ Araştırma } & & \multicolumn{2}{|l|}{ Derleme } & \\
\hline $\begin{array}{l}\text { Yazar } \\
\text { Soyadı/Yıl }\end{array}$ & Çalışmanın Başlığı & & $\begin{array}{l}\text { Yazar } \\
\text { Soyadı/Yll }\end{array}$ & Çalışmanın Başlığı & \\
\hline $\begin{array}{l}\text { Anderson, } \\
\text { Anderson ve } \\
\text { Shapiro, } 2004\end{array}$ & $\begin{array}{l}\text { Mathematical } \\
\text { discourse in shared } \\
\text { storybook reading }\end{array}$ & $\begin{array}{l}\text { Çocuk } \\
\text { kitaplarının } \\
\text { kullanılmasının } \\
\text { önemi }\end{array}$ & $\begin{array}{l}\text { Moyer, } \\
2000\end{array}$ & $\begin{array}{l}\text { Communicating } \\
\text { mathematically: } \\
\text { Children's literature } \\
\text { as a natural } \\
\text { connection }\end{array}$ & $\begin{array}{l}\text { Çocuk } \\
\text { kitaplarının } \\
\text { kullanılmasının } \\
\text { önemi }\end{array}$ \\
\hline $\begin{array}{l}\text { Young- } \\
\text { Loveridge, } \\
2004\end{array}$ & $\begin{array}{l}\text { Effects on early } \\
\text { numeracy of a } \\
\text { program using } \\
\text { number books and } \\
\text { games }\end{array}$ & $\begin{array}{l}\text { Çocuk } \\
\text { kitaplarının } \\
\text { kullanılmasının } \\
\text { önemi/ Çocuk } \\
\text { kitaplarının } \\
\text { nasıl } \\
\text { kullanılacağı }\end{array}$ & $\begin{array}{l}\text { Merenda, } \\
2000\end{array}$ & $\begin{array}{l}\text { Numeracy } \\
\text { encounters in a book } \\
\text { bag: Meeting the } \\
\text { NCTM Standards }\end{array}$ & $\begin{array}{l}\text { Çocuk } \\
\text { kitaplarının } \\
\text { nasıl } \\
\text { kullanılacağ1 }\end{array}$ \\
\hline $\begin{array}{l}\text { Cotti ve } \\
\text { Schiro, } 2004\end{array}$ & $\begin{array}{l}\text { Connecting teacher } \\
\text { beliefs to the use of } \\
\text { children's literature } \\
\text { in the teaching of } \\
\text { mathematics }\end{array}$ & $\begin{array}{l}\text { Çocuk } \\
\text { kitaplarının } \\
\text { nasıl } \\
\text { kullanılacağı }\end{array}$ & $\begin{array}{l}\text { Hellwig, } \\
\text { Monroe ve } \\
\text { Jacobs, } \\
2000\end{array}$ & $\begin{array}{l}\text { Making informed } \\
\text { choices: Selecting } \\
\text { children's trade } \\
\text { books for } \\
\text { mathematics } \\
\text { instruction }\end{array}$ & $\begin{array}{l}\text { Çocuk } \\
\text { kitaplarının } \\
\text { kullanılmasının } \\
\text { önemi }\end{array}$ \\
\hline $\begin{array}{l}\text { O'neill, } \\
\text { Pearce ve } \\
\text { Pick, } 2004\end{array}$ & $\begin{array}{l}\text { Preschool children's } \\
\text { narratives and } \\
\text { performance on the } \\
\text { Peabody } \\
\text { Individualized } \\
\text { Achievement Test- } \\
\text { Revised: Evidence of } \\
\text { a relation between } \\
\text { early narrative and } \\
\text { later mathematical } \\
\text { ability }\end{array}$ & $\begin{array}{l}\text { Çocuk } \\
\text { kitaplarının } \\
\text { kullanılmasının } \\
\text { önemi }\end{array}$ & $\begin{array}{l}\text { Jacobs, } \\
2000\end{array}$ & $\begin{array}{l}\text { Selecting books in } \\
\text { Spanish to teach } \\
\text { mathematics }\end{array}$ & $\begin{array}{l}\text { Çocuk } \\
\text { kitaplarının } \\
\text { seçim kriterleri }\end{array}$ \\
\hline $\begin{array}{l}\text { Anderson, } \\
\text { Anderson ve } \\
\text { Shapiro, } 2005\end{array}$ & $\begin{array}{l}\text { Supporting multiple } \\
\text { literacies: Parents' } \\
\text { and children's } \\
\text { mathematical talk } \\
\text { within storybook } \\
\text { reading }\end{array}$ & $\begin{array}{l}\text { Çocuk } \\
\text { kitaplarının } \\
\text { kullanılmasının } \\
\text { önemi }\end{array}$ & $\begin{array}{l}\text { Thatcher, } \\
2001\end{array}$ & $\begin{array}{l}\text { Reading in the math } \\
\text { class: Selecting and } \\
\text { using picture books } \\
\text { for math } \\
\text { investigations }\end{array}$ & $\begin{array}{l}\text { Çocuk } \\
\text { kitaplarının } \\
\text { seçim kriterleri/ } \\
\text { Çocuk } \\
\text { kitaplarının } \\
\text { nasıl } \\
\text { kullanılacağı }\end{array}$ \\
\hline $\begin{array}{l}\text { Wilburne, } \\
\text { Napoli, Keat, } \\
\text { Dile, Trout ve } \\
\text { Decker, } 2007\end{array}$ & $\begin{array}{l}\text { Journeying into } \\
\text { mathematics through } \\
\text { storybooks: A } \\
\text { kindergarten study }\end{array}$ & $\begin{array}{l}\text { Çocuk } \\
\text { kitaplarının } \\
\text { nasıl } \\
\text { kullanılacağı }\end{array}$ & $\begin{array}{l}\text { Diffly, } \\
2001\end{array}$ & $\begin{array}{l}\text { Using literature to } \\
\text { teach K-1 math } \\
\text { concepts: An } \\
\text { annotated } \\
\text { bibliography and } \\
\text { suggested extension } \\
\text { activities }\end{array}$ & $\begin{array}{l}\text { Çocuk } \\
\text { kitaplarının } \\
\text { nasıl } \\
\text { kullanılacağı }\end{array}$ \\
\hline $\begin{array}{l}\text { Van den } \\
\text { Heuvel- }\end{array}$ & $\begin{array}{l}\text { Picture books as an } \\
\text { impetus for }\end{array}$ & $\begin{array}{l}\text { Çocuk } \\
\text { kitaplarının }\end{array}$ & Jenner, & $\begin{array}{l}\text { Experiencing and } \\
\text { understanding }\end{array}$ & $\begin{array}{l}\text { Çocuk } \\
\text { kitaplarının }\end{array}$ \\
\hline
\end{tabular}




\begin{tabular}{|c|c|c|c|c|c|}
\hline $\begin{array}{l}\text { Panhuizen ve } \\
\text { Van den } \\
\text { Boogaard, } \\
2008\end{array}$ & $\begin{array}{l}\text { kindergartners' } \\
\text { mathematical } \\
\text { thinking }\end{array}$ & $\begin{array}{l}\text { kullanılmasının } \\
\text { önemi }\end{array}$ & 2002 & $\begin{array}{l}\text { mathematics in the } \\
\text { midst of a story }\end{array}$ & $\begin{array}{l}\text { nasıl } \\
\text { kullanılacağ1 }\end{array}$ \\
\hline $\begin{array}{l}\text { Casey, Erkut, } \\
\text { Ceder, Mercer } \\
\text { ve Young, } \\
2008\end{array}$ & $\begin{array}{l}\text { Use of a storytelling } \\
\text { context to improve } \\
\text { girls' and boys' } \\
\text { geometry skills in } \\
\text { kindergarten }\end{array}$ & $\begin{array}{l}\text { Çocuk } \\
\text { kitaplarının } \\
\text { kullanılmasının } \\
\text { önemi }\end{array}$ & $\begin{array}{l}\text { Lachance, } \\
2002\end{array}$ & $\begin{array}{l}\text { Connecting } \\
\text { children's literature } \\
\text { and mathematics: An } \\
\text { overview of ideas, } \\
\text { sources and resources }\end{array}$ & $\begin{array}{l}\text { Çocuk } \\
\text { kitaplarının } \\
\text { nasıl } \\
\text { kullanılacağ1 }\end{array}$ \\
\hline $\begin{array}{l}\text { Keat ve } \\
\text { Wilburne, } \\
2009\end{array}$ & $\begin{array}{l}\text { The impact of } \\
\text { storybooks on } \\
\text { kindergarten } \\
\text { children's } \\
\text { mathematical } \\
\text { achievement and } \\
\text { approaches to } \\
\text { learning }\end{array}$ & $\begin{array}{l}\text { Çocuk } \\
\text { kitaplarının } \\
\text { kullanılmasının } \\
\text { önemi }\end{array}$ & $\begin{array}{l}\text { Whitin, } \\
2002\end{array}$ & $\begin{array}{l}\text { The potentials and } \\
\text { pitfalls of integrating } \\
\text { literature into the } \\
\text { mathematics program }\end{array}$ & $\begin{array}{l}\text { Çocuk } \\
\text { kitaplarının } \\
\text { kullanılmasının } \\
\text { önemi }\end{array}$ \\
\hline $\begin{array}{l}\text { Elia, Van den } \\
\text { Heuvel- } \\
\text { Panhuizen ve } \\
\text { Georgiou, } \\
2010\end{array}$ & $\begin{array}{l}\text { The role of pictures } \\
\text { in picture books on } \\
\text { children's cognitive } \\
\text { engagement with } \\
\text { mathematics }\end{array}$ & $\begin{array}{l}\text { Çocuk } \\
\text { kitaplarının } \\
\text { kullanılmasının } \\
\text { önemi }\end{array}$ & $\begin{array}{l}\text { Clarke, } \\
2002\end{array}$ & $\begin{array}{l}\text { Making measurement } \\
\text { come alive with a } \\
\text { children's storybook }\end{array}$ & $\begin{array}{l}\text { Çocuk } \\
\text { kitaplarının } \\
\text { nasıl } \\
\text { kullanılacağı }\end{array}$ \\
\hline Marston, 2010 & $\begin{array}{l}\text { Developing a } \\
\text { framework for the } \\
\text { selection of picture } \\
\text { books to promote } \\
\text { early mathematical } \\
\text { development }\end{array}$ & $\begin{array}{l}\text { Çocuk } \\
\text { kitaplarının } \\
\text { kullanılmasının } \\
\text { önemi }\end{array}$ & $\begin{array}{l}\text { Cutler, } \\
\text { Gilkerson, } \\
\text { Parrott ve } \\
\text { Bowne, } \\
2003\end{array}$ & $\begin{array}{l}\text { Developing math } \\
\text { games based on } \\
\text { children's literature. }\end{array}$ & $\begin{array}{l}\text { Çocuk } \\
\text { kitaplarının } \\
\text { nasıl } \\
\text { kullanılacağ1 }\end{array}$ \\
\hline $\begin{array}{l}\text { Van den } \\
\text { Heuvel- } \\
\text { Panhuizen ve } \\
\text { Elia, 2011 }\end{array}$ & $\begin{array}{l}\text { Kindergartners' } \\
\text { performance in } \\
\text { length measurement } \\
\text { and the effect of } \\
\text { picture book reading }\end{array}$ & $\begin{array}{l}\text { Çocuk } \\
\text { kitaplarının } \\
\text { kullanılmasının } \\
\text { önemi }\end{array}$ & $\begin{array}{l}\text { McDuffie, } \\
\text { Young, } \\
2003\end{array}$ & $\begin{array}{l}\text { Promoting } \\
\text { mathematical } \\
\text { discourse through } \\
\text { children's literature }\end{array}$ & $\begin{array}{l}\text { Çocuk } \\
\text { kitaplarının } \\
\text { nasıl } \\
\text { kullanılacağ1 }\end{array}$ \\
\hline $\begin{array}{l}\text { Skoumpourdi } \\
\text { ve } \\
\text { Mpakopoulou, } \\
2011\end{array}$ & $\begin{array}{l}\text { The Prints: A picture } \\
\text { book for pre-formal } \\
\text { geometry }\end{array}$ & $\begin{array}{l}\text { Çocuk } \\
\text { kitaplarının } \\
\text { kullanılmasının } \\
\text { önemi }\end{array}$ & $\begin{array}{l}\text { Slanina, } \\
2003\end{array}$ & $\begin{array}{l}\text { Mathematics through } \\
\text { Literature in the } \\
\text { Early Childhood } \\
\text { Classroom }\end{array}$ & $\begin{array}{l}\text { Çocuk } \\
\text { kitaplarının } \\
\text { nasıl } \\
\text { kullanılacağ1 }\end{array}$ \\
\hline $\begin{array}{l}\text { Van den } \\
\text { Heuvel- } \\
\text { Panhuizen ve } \\
\text { Elia, } 2012\end{array}$ & $\begin{array}{l}\text { Developing a } \\
\text { framework for the } \\
\text { evaluation of picture } \\
\text { books that support } \\
\text { kindergartners' } \\
\text { learning of } \\
\text { mathematics }\end{array}$ & $\begin{array}{l}\text { Çocuk } \\
\text { kitaplarının } \\
\text { kullanılmasının } \\
\text { önemi }\end{array}$ & $\begin{array}{l}\text { Hunsader, } \\
2004\end{array}$ & $\begin{array}{l}\text { Mathematics Trade } \\
\text { Books: Establishing } \\
\text { their Value and } \\
\text { Assessing their } \\
\text { Quality }\end{array}$ & $\begin{array}{l}\text { Çocuk } \\
\text { kitaplarının } \\
\text { kullanılmasının } \\
\text { önemi }\end{array}$ \\
\hline $\begin{array}{l}\text { Öçal, Öçal ve } \\
\text { Şimşek, } 2015\end{array}$ & $\begin{array}{l}\text { Okul öncesi } \\
\text { öğrencilerine uygun } \\
\text { hikaye kitaplarında } \\
\text { geçen matematiksel } \\
\text { kavram ve becerilerin } \\
\text { incelenmesi }\end{array}$ & $\begin{array}{l}\text { Çocuk } \\
\text { kitaplarının } \\
\text { kullanılmasının } \\
\text { önemi }\end{array}$ & $\begin{array}{l}\text { Shih ve } \\
\text { Giorgis, } \\
2004\end{array}$ & $\begin{array}{l}\text { Building the } \\
\text { Mathematics and } \\
\text { Literature } \\
\text { Connection through } \\
\text { Children's Responses }\end{array}$ & $\begin{array}{l}\text { Çocuk } \\
\text { kitaplarının } \\
\text { nasıl } \\
\text { kullanılacağı }\end{array}$ \\
\hline $\begin{array}{l}\text { Van den } \\
\text { Heuvel- } \\
\text { Panhuizen, }\end{array}$ & $\begin{array}{l}\text { Effects of reading } \\
\text { picture books on } \\
\text { kindergartners' }\end{array}$ & $\begin{array}{l}\text { Çocuk } \\
\text { kitaplarının } \\
\text { kullanılmasının }\end{array}$ & $\begin{array}{l}\text { Casey, } \\
\text { Kersh ve } \\
\text { Young, }\end{array}$ & $\begin{array}{l}\text { Storytelling sagas: } \\
\text { An effective medium } \\
\text { for teaching early }\end{array}$ & $\begin{array}{l}\text { Çocuk } \\
\text { kitaplarının } \\
\text { nasıl }\end{array}$ \\
\hline
\end{tabular}




\begin{tabular}{|c|c|c|c|c|c|}
\hline $\begin{array}{l}\text { Elia ve } \\
\text { Robitzsch, } \\
2016\end{array}$ & $\begin{array}{l}\text { mathematics } \\
\text { performance }\end{array}$ & önemi & 2004 & $\begin{array}{l}\text { childhood } \\
\text { mathematics }\end{array}$ & kullanılacağ1 \\
\hline \multirow[t]{7}{*}{$\begin{array}{l}\text { Wikholm ve } \\
\text { Aerila, } 2016\end{array}$} & $\begin{array}{l}\text { Teaching } \\
\text { mathematics with } \\
\text { children's literature } \\
\text { in Finland }\end{array}$ & $\begin{array}{l}\text { Çocuk } \\
\text { kitaplarının } \\
\text { kullanılmasının } \\
\text { önemi }\end{array}$ & $\begin{array}{l}\text { Goral, } \\
\text { Gnadinger, } \\
2006\end{array}$ & $\begin{array}{l}\text { Using storytelling to } \\
\text { teach mathematics } \\
\text { concepts }\end{array}$ & $\begin{array}{l}\text { Çocuk } \\
\text { kitaplarının } \\
\text { nasıl } \\
\text { kullanılacağ1 }\end{array}$ \\
\hline & & & $\begin{array}{l}\text { Shatzer, } \\
2008\end{array}$ & $\begin{array}{l}\text { Picture book power: } \\
\text { Connecting } \\
\text { children's literature } \\
\text { and mathematics }\end{array}$ & $\begin{array}{l}\text { Çocuk } \\
\text { kitaplarının } \\
\text { kullanılmasının } \\
\text { önemi/ Çocuk } \\
\text { kitaplarının } \\
\text { nasıl } \\
\text { kullanılacağı }\end{array}$ \\
\hline & & & $\begin{array}{l}\text { Kinniburgh } \\
\text { ve Byrd, } \\
2008\end{array}$ & $\begin{array}{l}\text { Ten black dots and } \\
\text { September 11: } \\
\text { Integrating social } \\
\text { studies and } \\
\text { mathematics through } \\
\text { children's literature }\end{array}$ & $\begin{array}{l}\text { Çocuk } \\
\text { kitaplarının } \\
\text { kullanılmasının } \\
\text { önemi/ Çocuk } \\
\text { kitaplarının } \\
\text { nasıl } \\
\text { kullanılacağı }\end{array}$ \\
\hline & & & $\begin{array}{l}\text { Van den } \\
\text { Heuvel- } \\
\text { Panhuizen, } \\
\text { Van den } \\
\text { Boogaard } \\
\text { ve Doig, } \\
2009\end{array}$ & $\begin{array}{l}\text { Picture books } \\
\text { stimulate the learning } \\
\text { of mathematics }\end{array}$ & $\begin{array}{l}\text { Çocuk } \\
\text { kitaplarının } \\
\text { kullanılmasının } \\
\text { önemi/ Çocuk } \\
\text { kitaplarının } \\
\text { nasıl } \\
\text { kullanılacağı }\end{array}$ \\
\hline & & & $\begin{array}{l}\text { Jenkins, } \\
2010\end{array}$ & $\begin{array}{l}\text { Positioning Picture } \\
\text { Books within the } \\
\text { Mathematics } \\
\text { Curriculum }\end{array}$ & $\begin{array}{l}\text { Çocuk } \\
\text { kitaplarının } \\
\text { nasıl } \\
\text { kullanılacağ1 }\end{array}$ \\
\hline & & & $\begin{array}{l}\text { Marston, } \\
\text { Muir ve } \\
\text { Livy,2013 }\end{array}$ & $\begin{array}{l}\text { Can we really count } \\
\text { on Frank? Teach }\end{array}$ & $\begin{array}{l}\text { Çocuk } \\
\text { kitaplarının } \\
\text { nasıl } \\
\text { kullanılacağ1 }\end{array}$ \\
\hline & & & $\begin{array}{l}\text { Flevares ve } \\
\text { Schiff, } \\
2014\end{array}$ & $\begin{array}{l}\text { Learning } \\
\text { mathematics in two } \\
\text { dimensions: A } \\
\text { review and look } \\
\text { ahead at teaching and } \\
\text { learning early } \\
\text { childhood } \\
\text { mathematics with } \\
\text { children's literature }\end{array}$ & $\begin{array}{l}\text { Çocuk } \\
\text { kitaplarının } \\
\text { kullanılmasının } \\
\text { önemi }\end{array}$ \\
\hline
\end{tabular}

Ulaşılan makalelerin 23 tanesi derleme, 17 tanesi ise araştırma makalesi türünde desenlenmiştir. Makalelerde ele alınan temaların, çocuklara matematik becerilerinin kazandırılmasında çocuk kitaplarının kullanılmasının önemi ve çocuk kitaplarının nasıl kullanılacağına yönelik olduğu görülmektedir. Bir çalışmada çocuk kitaplarının nasıl kullanılacağının yanı sıra çocuk kitaplarının kullanımına ilişkin öğretmen görüşlerine de yer verilmiştir (Cotti ve Schiro, 2004). 
Araştırma türü makalelerin 14'ünde çocuk kitaplarının kullanılmasının önemi, ikisinde çocuk kitaplarının nasıl kullanılacağı, bir makalede ise çocuk kitaplarının kullanılmasının önemi ve çocuk kitaplarının nasıl kullanılacağı tema olarak belirlenmiştir.

Derleme türü çalışmaların 13'ünde çocuk kitaplarının nasıl kullanılacağı, beşinde çocuk kitaplarının kullanılmasının önemi, birinde çocuk kitaplarının seçim kriterleri, birinde çocuk kitaplarının seçim kriterleri ve çocuk kitaplarının nasıl kullanılacağı, üçünde çocuk kitaplarının kullanılmasının önemi ve çocuk kitaplarının nasıl kullanılacağı ele alınmıştır.

Araştırmanın dördüncü ve beşinci amacı ise, türü araştırma olan makalelerin araştırma yöntemlerinin ve hangi çalışma gruplarında yapıldığının belirlenmesidir. $\mathrm{Bu}$ amaç kapsaminda elde edilen bulgular Tablo 3 'de yer almaktadır.

Tablo 3. Erken çocukluk döneminde çocuk kitaplarının matematik becerilerinin kazandırılması konusunda yapılan araştırma makalelerinin kullanılan yöntem ve çalışma grubuna göre dağılımı

\begin{tabular}{|c|c|c|c|}
\hline \multicolumn{2}{|r|}{ Araştırma } & \multirow[b]{2}{*}{$\begin{array}{l}\text { Kullanılan } \\
\text { Yöntem }\end{array}$} & \multirow[b]{2}{*}{ Çalışma Grubu } \\
\hline $\begin{array}{l}\text { Yazar } \\
\text { Soyadı/Yıl }\end{array}$ & Çalışmanın Başı̆ı̆ı & & \\
\hline $\begin{array}{l}\text { Anderson, } \\
\text { Anderson ve } \\
\text { Shapiro, } 2004\end{array}$ & Mathematical discourse in shared storybook reading & Nitel & Okul öncesi dönem \\
\hline $\begin{array}{l}\text { Young- } \\
\text { Loveridge, } \\
2004\end{array}$ & $\begin{array}{l}\text { Effects on early numeracy of a program using number } \\
\text { books and games }\end{array}$ & Nicel & Okul öncesi dönem \\
\hline $\begin{array}{l}\text { Cotti ve } \\
\text { Schiro, } 2004\end{array}$ & $\begin{array}{l}\text { Connecting teacher beliefs to the use of children's } \\
\text { literature in the teaching of mathematics }\end{array}$ & Nitel & $\begin{array}{l}\text { Öğretmen ve alan } \\
\text { uzmanları }\end{array}$ \\
\hline $\begin{array}{l}\text { O'neill, Pearce } \\
\text { ve Pick, } 2004\end{array}$ & $\begin{array}{l}\text { Preschool children's narratives and performance on } \\
\text { the Peabody Individualized Achievement Test- } \\
\text { Revised: Evidence of a relation between early } \\
\text { narrative and later mathematical ability }\end{array}$ & Nicel & Okul öncesi dönem \\
\hline $\begin{array}{l}\text { Anderson, } \\
\text { Anderson ve } \\
\text { Shapiro, } 2005\end{array}$ & $\begin{array}{l}\text { Supporting multiple literacies: parents' and children's } \\
\text { mathematical talk within storybook reading }\end{array}$ & Nitel & Okul öncesi dönem \\
\hline $\begin{array}{l}\text { Wilburne, } \\
\text { Napoli, Keat, } \\
\text { Dile, Trout ve } \\
\text { Decker, } 2007\end{array}$ & $\begin{array}{l}\text { Journeying into mathematics through storybooks: A } \\
\text { kindergarten study. }\end{array}$ & Nitel & $\begin{array}{l}\text { Öğretmen ve alan } \\
\text { uzmanları }\end{array}$ \\
\hline $\begin{array}{l}\text { Van den } \\
\text { Heuvel- } \\
\text { Panhuizen ve } \\
\text { Van den } \\
\text { Boogaard, } \\
2008\end{array}$ & $\begin{array}{l}\text { Picture books as an impetus for kindergartners' } \\
\text { mathematical thinking. }\end{array}$ & Nitel & Okul öncesi dönem \\
\hline $\begin{array}{l}\text { Casey, Erkut, } \\
\text { Ceder, Mercer } \\
\text { ve Young, }\end{array}$ & $\begin{array}{l}\text { Use of a storytelling context to improve girls' and } \\
\text { boys' geometry skills in kindergarten. }\end{array}$ & Nicel & Okul öncesi dönem \\
\hline
\end{tabular}




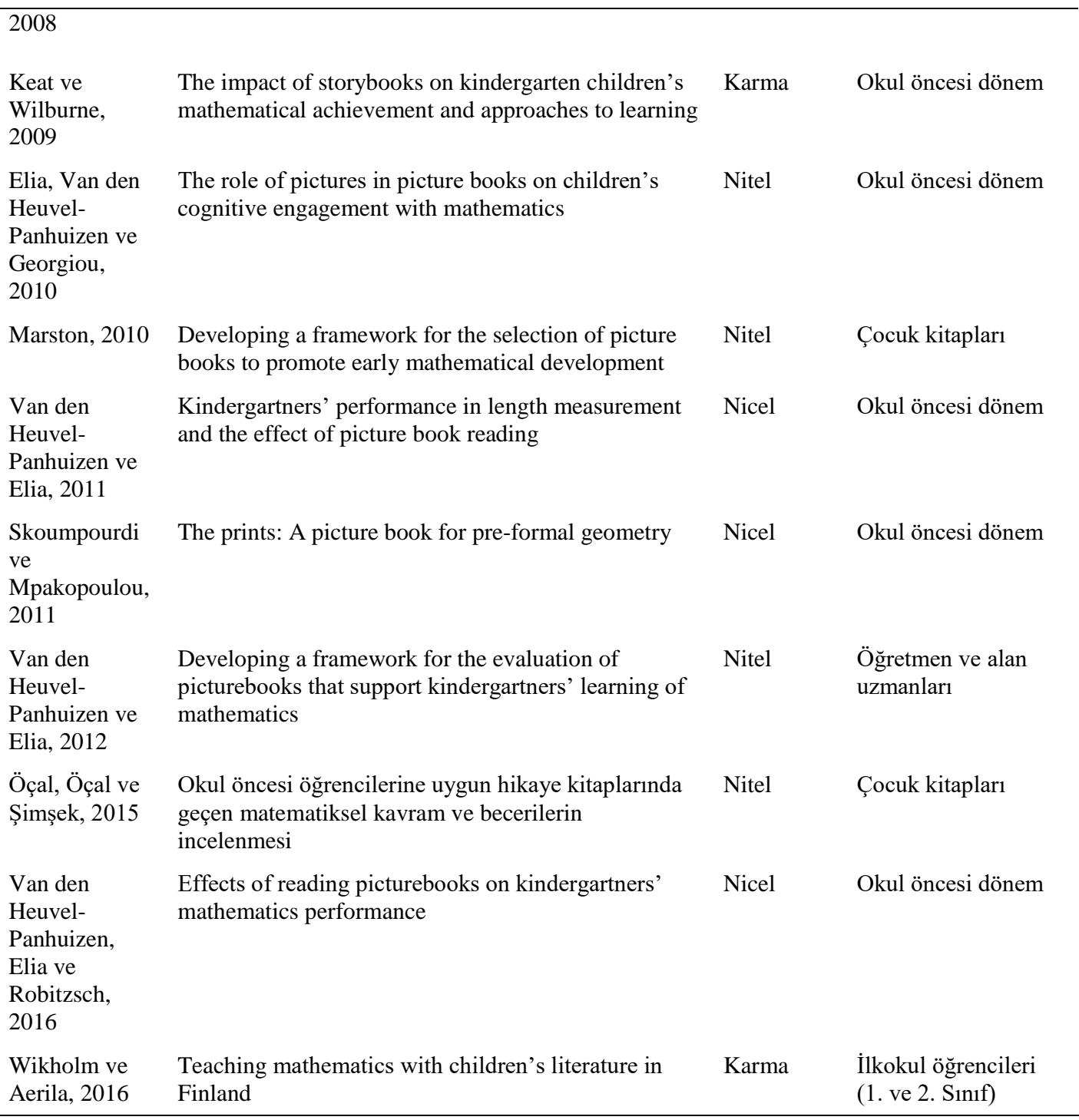

Araştırmaların yöntemleri incelendiğinde, dokuz çalışmanın nitel, altı çalışmanın nicel, iki çalışmanın ise karma araştırma yöntemi ile gerçekleştirildiği belirlenmiştir. Erken çocukluk döneminde çocuk kitaplarının matematik becerilerinin kazandırılması amacıyla kullanılması konusunda yapılan araştırmaların büyük bir çoğunluğunun çalışma grubunu okul öncesi dönemdeki çocukların ( $f=11$ ) oluşturduğu, ilkokul öğrencileri (1. ve 2. sınıf) ile bir, öğretmen ve alan uzmanları ile üç çalışma yapıldığı görülmektedir. Çocuk kitapları üzerine ise iki çalışmaya rastlanılmıştır.

\section{Tartışma ve Sonuç}

$\mathrm{Bu}$ araştırma, ulusal ve uluslararası düzeyde erken çocukluk döneminde matematik becerilerinin kazandırılmasında çocuk kitaplarının kullanılmasına ilişkin 2000-2016 yılları arasında yapılmış olan çalışmaların durumunu değerlendirmek amacıyla yapılmış, ancak 
ulusal düzeyde konuya ve erken çocukluk dönemine ilişkin sadece bir yayın olması nedeniyle bu yayın dışında, araştırma uluslararası düzeyde yapılan çalışmalarla sınırlı kalmıştır. Verilerin analizinde araştırmanın alt amaçları doğrultusunda araştırmanın yılı, makalelerin araştırma türü ve deseni, kullanılan araştırma yöntemleri, çalışma grupları ve temalar olmak üzere beş kategori oluşturulmuştur.

Araştırma sonucunda, 2000-2016 yılları arasında, konuya ilişkin sınırlı sayıda çalışmanın olduğu görülmektedir. Ülkemizde ise Veziroğlu ve Gönen (2012) tarafindan gerçekleştirilen "Resimli Çocuk Kitaplarının M.E.B. 2006 Okul Öncesi Eğitim Programı'ndaki Kazanımlara Uygunluğunun İncelenmesi” başlıklı çalışmada; özellikle sayma, sıralama, toplama-çıkarma, geometrik şekiller, semboller, grafik gibi matematik becerilerini içeren kazanımların kitaplarda çok az desteklendiği sonucuna ulaşılmıştır. İlter (2014) ise ilkokul ve ortaokul sosyal bilgiler ve matematik öğretim programlarına yönelik çocuk kitaplarında sosyal bilgiler ile matematiğin bütünleştirilmesini incelemiştir. Bu çalışmadan elde edilen bulgulara göre, çalışma kapsamına alınan kitaplar ile sosyal bilgilerin matematikle bütünleştirilmesinin sağlanabilirliği ortaya çıkmıştır. Ancak incelenen materyallerde sosyal bilgilerin daha çok "İnsanlar, yerler ve çevreler" ve "Üretim, tüketim ve dağıtım" öğrenme alanları kapsamındaki kavram ve becerilerin matematikle bütünleştirildiği saptanmıştır. Öçal, Öçal ve Şimşek (2015) okul öncesi çocuklarına yönelik hikâye kitaplarında geçen matematiksel kavram ve becerileri incelediği çalışmada, sayma, uzamsal algı ve zaman kavramlarına çok fazla yer verildiğini, örüntü, işlem ve grafik becerilerine ise çok az yer verildiğini belirlemişlerdir. Görüldüğü gibi, ülkemizde çocuk kitapları aracılığı ile matematik becerilerinin kazandırılmasının önemine, çocuk kitaplarının bu amaçla nasıl kullanılacağına ilişkin çalışmalar bulunmamaktadır.

2004 yılında yurtdışında erken çocukluk döneminde çocuk kitaplarının matematik becerilerinin kazandırılması amacı ile kullanılması konusunda yapılan araştırmalar da önemli derecede bir artış olduğu ve bu araştırmaların çoğunluğunun derleme türünde olduğu görülmektedir. Bununla birlikte son yıllarda yapılan çalışmalarda araştırma türünde desenlenen çalışmalarda bir artış olduğu göze çarpmaktadır.

İncelenen çalışmalarda, sırası ile çocuklara matematik becerilerinin kazandırılması, çocuk kitaplarının kullanılmasının önemi, çocuk kitaplarının nasıl kullanılacağı ve seçim kriterleri ele alınmıştır. Bu sonuç doğrultusunda farklı matematiksel kavram ve becerileri destekleyici çocuk kitaplarını seçmeye yönelik öğretmen yeterliklerini inceleyen çalışmaların yapılması gerekli görülmektedir.

Derleme türü çalışmalarda çoğunlukla çocuk kitaplarının nasıl kullanılacağına ilişkin örneklerin yer aldığı görülmektedir (Merenda, 2000; Diffly, 2001; Lachance, 2002; Cutler, Gilkerson, Parrott ve Bowne, 2003; Shih ve Giorgis, 2004; Goral, Gnadinger, 2006; Jenkins, 2010; Marston, Muir ve Livy, 2013). Araştırma türü makalelerin çoğunluğunda ise çocuk kitaplarının kullanılmasının önemine dayalı olarak eğitsel programların hazırlandığı deneysel çalışmaların yer aldığı (Young-Loveridge, 2004; Casey, Erkut, Ceder, Mercer ve Young, 2008; Van den Heuvel-Panhuizen ve Elia, 2011; Van den Heuvel-Panhuizen, Elia ve Robitzsch, 2016), aynı zamanda ebeveyn ve öğretmenlerin kitap okuma etkinlikleri sırasında kullandıkları matematiksel kavramların tespit edilmesine yönelik çalışmaların olduğu belirlenmiştir (Anderson, Anderson ve Shapiro, 2004; Anderson, Anderson ve Shapiro, 2005; Elia, Van den Heuvel-Panhuizen ve Georgiou, 2010). Bu çalışmalar çocuk kitapları ile matematik kavram ve becerilerinin nasıl kazandırılacağına yönelik örnekler sunması açısından önemlidir. 
Araştırmadan elde edilen bir diğer sonuç ise araştırma türündeki çalışmaların çoğunda nitel yöntemin kullanılması, hem nitel hem de nicel araştırma yöntemlerinin birlikte kullanıldığı karma araştırma türünde ise sadece iki araştırmanın olmasıdır. Oysaki nicel ve nitel araştırma yöntemlerinin bir arada kullanılması, daha bütüncül bir anlayış sağlayarak, araştırılan olayın çeşitli yönlerini açıklamaya yardımcı olmaktadır (Fielding ve Fielding, 1986; Davies, 2000). İki yöntemin birbirini desteklemesi ve onaylaması, ayrıntılı ve gelişmiş bir analiz yapılmasına olanak vermesi, oluşan yeni anlayışlarla düşülen çelişkiler sonucunda yeni araştırma konularının ortaya çıkabilmesi, iki yöntem arasında gerçekleşen sentez ile yöntemlerin eksiklerinin giderilmesi ve araştırmanın güvenirliği açısından firsat oluşmaktadır. Böylece tek bir yöntemin zayıflığının giderilmesine, bütün bir resmin görülebilmesine, sayısal ve sözel değerlerin beraber kullanımı ile açıklama kolaylığının sağlanmasına ve yine aynı şekilde açıklamanın anlam gücünün artmasına yardımcı olacaktır (Rossman ve Wilson, 1994).

$\mathrm{Bu}$ araştırmada matematik becerilerinin kazandırılmasında erken çocukluk dönemini kapsayan çocuk kitaplarının kullanılmasına yönelik yapılan çalışmalar incelenmiştir, buna bağlı olarak en çok okul öncesi döneme yönelik çalışmaların olduğu görülmektedir. Okul öncesi dönemde edinilen matematik ile ilgili bilgi, beceri ve deneyimler, çocuğun daha sonraki okul yaşamı için gerekli olan matematik bilgisi ve kavramların temelini oluşturmakta ve ileriki yıllarda matematik alanında çocukların başarılı olmalarında önemli rol oynamaktadır. Bu nedenle matematiği keşfetmeye dayalı çalışmalar bu dönemin önemli bir parçası olmalıdır (Akman, 2002; Brown, Molfese ve Molfese, 2008; Sarama ve Clements, 2009; Çelik ve Kandır, 2013). Aynı zamanda çocuk kitapları çocukları herhangi bir matematiksel kavram ya da beceriye hazırlamakta, bu kavram ve becerileri geliştirmekte ve yaratıcı bir matematik deneyimine olanak sağlamaktadır (Welchman-Tischler, 1992). Bu nedenle okul öncesi dönemdeki çocuklara yönelik çalışmaların çoğunlukta olması olumlu bir durum olarak görülmekle birlikte, çocuk kitapları ile farklı matematiksel kavram ve becerilerinin nasıl destekleneceğine yönelik uygulamaya dönük çalışmaların da yetersiz olduğu belirlenmiştir.

Araştırma sonuçları, çocuk kitapları yoluyla matematik becerilerinin kazandırılmasına ilişkin yapılan çalışmaların ve bu konudaki eksiklikleri ortaya koymaktadır. Bu eksikliklerin konuya ilişkin çalışma yapacak araştırmacılara yol göstereceği düşünülmektedir. $\mathrm{Bu}$ doğrultuda çocuk kitapları yoluyla matematik kavram ve becerilerini kazandırmaya yönelik deneysel çalışmaların yapılması ve özellikle bu çalışmalarda çocuk kitapları aracılığı ile matematik kavram ve becerilerinin nasıl kazandırılacağına yönelik örnekler sunulması, çalışmanın kapsamının genişletilerek daha geniş bir yıl aralığının ele alınması ve yapılacak araştırmalarda karma araştırma yöntemlerinin benimsenmesi önerilebilir. 


\section{Kaynakça}

AKMAN, B. (2002). Okul öncesi dönemde matematik. Hacettepe Üniversitesi Eğitim Fakültesi Dergisi, 23, 244-248.

*ANDERSON, A., ANDERSON, J., \& SHAPÍRO, J. (2004). Mathematical discourse in shared storybook reading. Journal for Research in Mathematics Education, 35 (1) 533. doi: $10.2307 / 30034801$.

*ANDERSON, A., ANDERSON, J., \& SHAPİRO, J. (2005). Supporting multiple literacies: parents' and children's mathematical talk within storybook reading. Mathematics Education Research Journal, 16 (3), 5-26.

ARNOLD, D. H., FISCHER, P. H., DOCTOROFF, G. L., \& DOBBS, J. (2002). Accelerating math development in Head Start classrooms. Journal of Educational Psychology, 94 (4), 762-770.

AVCI, N. ve DERE, H. (2002). Okul öncesi çocuğu ve matematik. V. Ulusal Fen Bilimleri ve Matematik Eğitimi Kongresi içi:. www.fedu.metu.edu.tr/ufbmek5/b_kitabi/PDF/OkulOncesi/.../ t262d.pdf] Erişi Tarihi: 25 Haziran 2017.

BOALER, J. \& CHEN, L. (2016). Why kids should use their fingers in math class. [Çevrimiçi: http://www.theatlantic.com/education/archive/2016/04/why-kids-should-use-theirfingers-in-math-class/478053/]. Erişi Tarihi: 25 Haziran 2017.

BROWN, E. T., Molfese, V. J., \& Molfese, P. (2008). Preschool student learning in literacy and mathematics: Impact of teacher experience, qualifications, and beliefs on an atrisk sample. Journal of Education for Students Placed at Risk (JESPAR), 13 (1), 106126. doi:10.1080/10824660701860474

CALLAN, R. (2004). Reading+ math= A perfect match. Teaching Pre K-8, 34 (4), 50-51.

CAPRARO, R. M., \& CAPRARO, M. M. (2006). Are you really going to read us a story? Learning geometry through children's mathematics literature. Reading Psychology, 27 (1), 21-36.

*CASEY, B., KERSH, J. E., \& YOUNG, J. M. (2004). Storytelling sagas: An effective medium for teaching early childhood mathematics. Early Childhood Research Quarterly, 19 (1), 167-172.

*CASEY, B., ERKUT, S., CEDER, I., \& MERCER YOUNG, J. (2008). Use of a storytelling context to improve girls' and boys' geometry skills in kindergarten. Journal of Applied Developmental Psychology, 29, 29-48.

*CLARKE, D. (2002). Making measurement come alive with a children's storybook. Australian Primary Mathematics Classroom, 7 (3), 9-13.

CLEMENTS, D. H., \& SARAMA, J. (2009). Learning and teaching early math: The learning trajectories approach. New York: Routledge.

COHEN, L., MANION, L., \& MORRISON, K. (2007). Research methods in education (6th ed.). New York, NY: Routledge.

*COTTI, R., \& SCHIRO, M. (2004). Connecting teacher beliefs to the use of children's literature in the teaching of mathematics. Journal of Mathematics Teacher Education, 7 (4), 329-356. 
*CUTLER, K. M., GILKERSON, D., PARROTT, S., \& BOWNE, M. T. (2003). Developing math games based on children's literature. Young Children, 58 (1), 22-27.

ÇELIK, M. ve KANDIR, A. (2013). 61-72 aylık çocukların matematik gelişimine "Küçük çocuklar için büyük matematik (Big math for little kids)" eğitim programının etkisi. Kuramsal Eğitim Bilim Dergisi, 6, 551-567.

DAVIES, P. (2000). Contributions from qualitative research. In H. T. Davies, M. N. Sandra, \& P. Smith (Eds). What works? Evidence-based Policy and Practice in Public Services (pp.291- 316), Bristol, UK: Policy Press.

*DIFFLY, D. (2001). Using literature to teach K-1 math concepts: An annotated bibliography and suggested extension activities. [Çevrim-içi: http://eric.ed.gov/?id=ED456932] Erişi tarihi: 25 Haziran 2017.

DİNÇER, Ç. (2008). Okul öncesi eğitimde matematik. Uluslararası Çocuk, Aile ve Okul Bağlamında Okul Öncesi Ĕ̈itim Kongre Kitabı, 55-60.

*ELIA, I., VAN DEN HEUVEL-PANHUIZEN, M., \& GEORGIOU, A. (2010). The role of pictures in picturebooks on children's cognitive engagement with mathematics. European Early Childhood Education Research Journal, 18 (3), 125-147.

EMIROĞLU H. ve GÖRGÜLÜ, N. (2013). Hukukun matematiksel olarak ifade edilmesi, Ankara Üniversitesi Hukuk Fakültesi Dergisi, 62 (1), 73-92.

FIELDING, N., \& FIELDING, J. (1986). Linking data: The articulation of qualitative and quantitative methods in social research. Beverly Hills, CA: Sage.

*FLEVARES, L.M. \& SCHIFF, J.R. (2014). Learning mathematics in two dimensions: a review and look ahead at teaching and learning early childhood mathematics with children's literature. Front Psychol. 2014 (5), 1-12. doi: 10.3389/fpsyg.2014.00459.

GOLDSTEIN, J. E. (2007). The integration of children's literature into mathematics. Unpublished master thesis. College for Professional Studies Graduate Programs Regis University, Denver.

[Çevrim-içi: http://epublications.regis.edu/cgi/viewcontent.cgi?article=1027\&context=theses] Erişi Tarihi: 25 Haziran 2017.

*GORAL, M. B., \& GNADİNGER, C. M. (2006). Using storytelling to teach mathematics concepts. Australian Primary Mathematics Classroom, 11 (1), 4-8.

GÜVEN, Y. (2000). Erken çocukluk döneminde sezgisel düşünme ve matematik. İstanbul: Ya-Pa Yayınları.

*HELLWIG, S. J., MONROE, E. E., \& JACOBS, J. S. (2000). Making informed choices: Selecting children's trade books for mathematics instruction. Teaching Children Mathematics, 7 (3), 138-143.

*HUNSADER, P. (2004). Mathematics Trade Books: Establishing their value and assessing their quality. The Reading Teacher, 57 (7), 618-629.

İLTER, İ. (2014). Çocuk edebiyatı aracılığıyla sosyal bilgilerin matematikle bütünleștirilmesi. Journal of Human Sciences, 11 (2), 1117-1138. doi: 10.14687/ijhs.v11i2.2839.

*JACOBS, V.R. (2000). Selecting books in Spanish to teach mathematics. Teaching 
Children Mathematics 6 (9), 582-587.

*JENKINS, K. (2010). Positioning picture books within the mathematics curriculum. Australian Primary Mathematics Classroom, 15 (2), 28-32.

*JENNER, D. M. (2002). Experiencing and understanding mathematics in the midst of a story. Teaching Children Mathematics, 9, 167-171.

KARADAĞ, R. (2014). Dünyada ve Türkiye'de farklılaştırılmış öğretimle ilgili yapılmış çalışmaların değerlendirilmesi. Kastamonu Eğitim Dergisi, 22 (3), 1301-1322.

*KEAT, J. \& WILBURNE, J. (2009). The impact of storybooks on kindergarten children's mathematical achievement and approaches to learning. US China Education Review, 6 (7), 61-67.

*KINNIBURGH, L. H., \& BYRD, K. (2008). Ten black dots and September 11: Integrating social studies and mathematics through children's literature. The Social Studies, 99 (1), 33-36.

KİPATRİCK, J.; SWAFFORD, J., \& FINDELL, B. (2001). Adding it up: Helping children learn mathematics. Washington, DC: National Academy Press.

*LACHANCE, A. (2002). Connecting children's literature and mathematics: An overview of ideas, sources and resources. Language and Literacy Spectrum, 12, 13-22.

*MARSTON, J. (2010). Developing a framework for the selection of picture books to promote early mathematical development. ERIC Digest (ED520914). Columbus, OH: ERIC Clearinghouse for Science, Mathematics, and Environmental Education. [Çevrim-içi: http://files.eric.ed.gov/fulltext/ED520914.pdf] Erişi Tarihi: 25 Haziran 2017.

*MARSTON, J., MUIR, T. \& LIVY, S. (2013). Can we really count on Frank? Teaching Children Mathematics 19(7), 440-448.

*MCDUFFIE, A. M. R., \& Young, T. A. (2003). Promoting mathematical discourse through children's literature. Teaching Children Mathematics, 9, 385-389.

*MERENDA, R.C. (2000). Numeracy encounters in a book bag: Meeting the NCTM Standards. Early Childhood Education Journal, 27 (3), 151-157.

METíN, N. (2001). Okul öncesi çocuklarda matematik kavramlarının gelişimi. Çocuk Gelişimi ve Eğitimi Dergisi, 1, 22-26.

*MOYER, P. S. (2000). Communicating mathematically: Children's literature as a natural connection. The Reading Teacher, 54 (3), 246-255.

MURPHY, S. J. (1999). Learning math through stories. School Library Journal, 45 (3), 122123.

NAEYC (National Association for the education of young children/national council of teachers of mathematics). (2002). Early childhood mathematics: Promoting good beginnings. Washington, DC: National Association for the Education of Young Children. [Çevrim-içi: https://www.naeyc.org/files/naeyc/file/positions/psmath.pdf]. Erişi Tarihi: 25 Haziran 2017.

NESİN, A. (2001). Matematik ve doğa. İstanbul: İstanbul Bilgi Üniversitesi Yayınları. 
*O'NEILLL, D. K., PEARCE, M. J., \& PİCK, J. L. (2004). Preschool children's narratives and performance on the Peabody Individualized Achievement Test-Revised: Evidence of a relation between early narrative and later mathematical ability. First Language, 24 (2), 149-183.

*ÖÇAL, T , ÖÇAL, M , ŞİMŞEK, M . (2015). Okul öncesi öğrencilerine uygun hikaye kitaplarında geçen matematiksel kavram ve becerilerin incelenmesi. Current Research in Education, 1 (2), 58-69. [Çevrim-içi: http://www.e-dergimarmara.dergipark.gov.tr/crd/issue/4123/54221] Erişi Tarihi: 25 Haziran 2017.

PERRY, B.\& DOCKETT, S.(2005). I know that you don't have to work hard: Mathematics learning in the first year of primary school. In Helen L. Chick \& Jill L. Vincent (Eds.), Proceedings of the 29th annual conference of the International Group for the Psychology of Mathematics Education (Vol. 4, pp. 65-72). Melbourne: University of Melbourne.

RADEBAUGH M. R. (1981). Using children's literature to teach mathematics. The Reading Teacher, 34 (8), 902-906

ROSSMAN, G. B., \& WILSON, B. L. (1994). Numbers and words revisited: Being "shamelessly eclectic". Quality and Quantity, 28 (3), 315-327.

SARAMA, J. \& CLEMENTS, D. (2009). Early childhood mathematics learning: Learning trajectories for young children. New York: Routledge Taylor \& Francis Group.

*SHATZER, J. (2008). Picture book power: Connecting children's literature and mathematics. The Reading Teacher, 61 (8), 649-653.

*SHIH, J. C. \& GIORGIS, C. (2004). Building the mathematics and literature connection through children's responses. Teaching Children Mathematics, 10 (6), 328-333.

SIEBERT, D., \& DRAPER, J. R. (2008). Why content-area literacy messages do not speak to mathematics teachers: A critical content analysis. Literacy Research and Instruction, 47(4), 229-245. doi: 10.1080/19388070802300314.

*SKOUMPOURDİ, C., \& Mpakopoulou, I. (2011). The prints: A picture book for preformal geometry. Early Childhood Education Journal, 39 (3), 197-206.

*SLANINA, A. M. (2003). Mathematics through literature in the early childhood classroom. developmentally appropriate practice. Journal of Early Education and Family Review, 10 (5), 6-10.

SMITH, S. S. (2013). Early childhood mathematics. USA: Pearson Education Inc.

ŞİMŞEK, H. (2009). Eğitim tarihi araştırmalarında yöntem sorunu. Ankara Üniversitesi Eğitim Bilimleri Fakültesi Dergisi, 42 (1), 33-51.

*THATCHER, D. H. (2001). Reading in the math class: Selecting and using picture books for math investigations. Young Children, 56 (4), 20-26.

THOMAS, L., FENG, J. (2015). Integrating children's literature in elementary mathematics. Georgia Educational Research Association Annual Conference. [Çevrim-içi: http://files.eric.ed.gov/fulltext/ED560858.pdf]. Erişi Tarihi: 25 Haziran 2017.

TURAN, S. KARADAĞ, E., BEKTAŞ, F. ve YALÇIN, F. (2014). Türkiye'de eğitim yönetiminde bilgi üretimi: Kuram ve Uygulamada Eğitim Yönetimi Dergisi 2003- 
2013 yayınlarının incelenmesi. Kuram ve Uygulamada Eğitim Yönetimi, 20 (1), 93119.

*VAN DEN HEUVEL-PANHUIZZEN, M., \& VAN DEN BOOGAARD, S. (2008). Picture books as an impetus for kindergartners' mathematical thinking. Mathematical Thinking and Learning, 10 (4), 341-373.

*VAN DEN HEUVEL-PANHUIZEN, M., VAN DEN BOOGAARD, S., \& DOİG, B. (2009). Picture books stimulate the learning of mathematics. Australian Journal of Early Childhood, 34 (3), 30-39.

*VAN DEN HEUVEL-PANHUIZEN, M. \& ELIA. I., (2011). Kindergartners' performance in length measurement and the effect of picture book reading. The International Journal on Mathematics Education, 43 (5), 621-635.

*VAN DEN HEUVEL-PANHUIZEN, M., \& ELIA, I. (2012). Developing a framework for the evaluation of picture books that support kindergartners' learning of mathematics', Research in Mathematics Education, 14 (1), 17-47.

*VAN DEN HEUVEL-PANHUIZEN, M., ELIA, I., \& ROBITZSCH, A. (2016). Effects of reading picturebooks on kindergartners' mathematics performance. Educational Psychology, 36 (2) 323-346.

VEZIROĞLU, M. ve GÖNEN, M. (2012). Resimli çocuk kitaplarının MEB Okul Öncesi Eğitim Programı'ndaki kazanımlara uygunluğunun incelenmesi. Eğitim ve Bilim, 37 (163), 226-238.

WELCHMAN-TISCHLER, R. (1992). How to use children's literature to teach mathematics. Reston, VA: National Council of Teachers of Mathematics.

*WHITIN, D.J. (2002). The potentials and pitfalls of integrating literature into the mathematics program. Teaching Children Mathematics, 8 (9), 503-504.

*WIKHOLM, M. \& AERILA, J.A. (2016). Teaching mathematics with children's literature in Finland. International Journal of Learning and Teaching. 8 (4), 253-261.

*WILBURNE, J., NAPOLI, M., KEAT, J., DILE, K., TROUT, M. \& DECKER, S. (2007). Journeying into mathematics through storybooks: A kindergarten study. Teaching Children Mathematics, 14(4), 232-237.

WILBURNE, J. M., \& NAPOLİ, M. (2008). Connecting mathematics and literature: An analysis of pre-service elementary school teachers' changing beliefs and knowledge. Issues in the Undergraduate Mathematics Preparation of School Teachers, 2, 1-10.

WORTHAM, C. S. (1998). Early childhood curriculum developmental bases for leaming and teaching (Second Edition). USA: Prentice Hall, Inc.

YILDIRIM, A. ve Şimşek, H. (2000). Sosyal bilimlerde nitel araştırma yöntemleri. Gözden geçirilmiş 2. Baskı. Ankara: Seçkin Yayıncılık.

*YOUNG-LOVERIDGE, J. M. (2004). Effects on early numeracy of a program using number books and games. Early Childhood Research Quarterly, 19, 82-98.

* İşaretli çalışmalar dâhil edilmiştir. 